\title{
Effect of different diets on the biological parameters of rice moth, Corcyra cephalonica Stainton
}

\author{
P. RAJKUMARI, A. BASIT AND D. SHARMAH* \\ Department of Entomology, Assam Agricultural University, JORHAT (ASSAM) INDIA
}

\section{ARITCLE INFO}

Received : 10.06 .2014

Revised : 15.08 .2014

Accepted : 29.08.2014

\section{KEY WORDS :}

Corcyra cephalonica, Rice moth, Diet, Biological parameters

*Corresponding author:

Email: dasharmah@gmail.com

\begin{abstract}
The effect of different diets on the biological parameters of rice moth, Corcyra cephalonica Stainton (Lepidoptera: Pyralidae) was studied under laboratory condition during 2010 -2011 in the Department of Entomology, Assam Agricultural University, Jorhat, Assam. Among the six diets tested, rice, wheat and groundnut mixture (5:5:1) was found to be the superior rearing medium that enhanced quicker development period of Corcyra cephalonica, maximum fecundity and maximum fresh body weight of full grown larva for both summer and winter seasons. The quicker development period of Corcyra cephalonica were $36.30 \pm 0.58$ and $48.80 \pm 0.33$ in summer and winter, respectively whereas maximum fecundity were $175.60 \pm 0.13$ and $157.65 \pm 2.64$ in both the season. The maximum fresh body weight of full grown larva was $93.85 \pm 0.56$ in summer and $84.70 \pm 1.05$ in winter when Corcyra cephalonica reared in rice, wheat and groundnut mixture $(5: 5: 1)$. Groundnut alone proved to be the least preferred by the Corcyra cephalonica so weak performance in all the parameters for this tested host of many natural enemies.
\end{abstract}

How to view point the article : Rajkumari, P., Basit, A. and Sharmah, D. (2014). Effect of different diets on the biological parameters of rice moth, Corcyra cephalonica Stainton. Internat. J. Plant Protec., 7(2) :397-400. 